\title{
COVID-19 pandemic effect on female sexual function
}

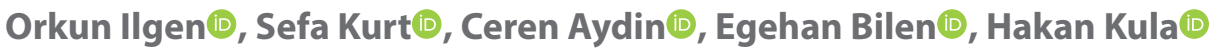 \\ Dokuz Eylul University School of Medicine Department of Obstetrics and Gynecology, Izmir, Turkey
}

\begin{abstract}
Objectives: To determine the COVID-19 pandemic's effect on female sexual functions among Turkish women.

Material and methods: The present study was performed by using the previous study data that was conducted before the pandemic to detect female sexual function by using questionnaires. Comparison of Female Sexual Function Index (FSFI), Beck Anxiety Inventory (BAI), and Beck Depression Inventory (BDI) scores in women during and before the pandemic. Participants were asked to fill questionnaire forms again.

Results: FSFI scores of the participants were higher before the pandemic, however, this finding was not statistically significant (21.8 vs $21.0, p=0.27$ ). BAl and BDI scores with high scores accompanied by anxiety and depression were found statistically significantly higher in the study (11.2 vs $13.3, p<0.01 ; 10.0$ vs $13.7, p<0.01$; respectively). BAl scores had a negative correlation with FSFI scores, however, BDI scores had not a significant correlation with FSFI scores in the present study $(p<0.01$, correlation coefficient $=-0.302 ; p=0.07$; correlation coefficient $=-0.183$; respectively).

Conclusions: Pandemic seems not to affect female sexual behavior. However, the pandemic is associated with anxiety and depression.
\end{abstract}

Key words: COVID-19; pandemic; female sexual function

Ginekologia Polska 2021; 92, 12: 856-859

\section{INTRODUCTION}

Coronavirus is a member of the RNA virus family that affect the respiratory system. As a result of that, common symptoms are fever, cough, and cold; however, the infection can be more serious in certain cases and has resulted in pneumonia and acute respiratory distress syndrome [1]. The COVID-19 infection is believed to have first started in China, then spreading throughout the world and declared as a pandemic by the World Health Organization on $11^{\text {th }}$ March 2020. At the time of writing this article, the confirmed case number was more than 33 million and the number of death was more than 997000 . Therefore most of the countries and states set strict rules including travel restrictions, closing borders, and quarantine [2].

Prevalence of female sexual dysfunction (FSD) is approximately $40 \%$ among women of all ages. Quality of life is impaired by the FSD [3]desire, arousal, and orgasm. Kissinger et al. [4], were determined that genital self-care was reduced after Hurricane Katrina. In another study that investigated the relationship between sexual behavior and Wenchuan earthquake showed that sexual intercourse frequency and satisfaction in women were reduced after the disaster [5]menstruation disorders, satisfaction with sexual life, and desire for fertility. RESULTS: The rates of symptoms of lower genital tract infection were higher after than before the earthquake $(50.0 \%$ vs $26.5 \%$ ).

Several studies have investigated the relationship between female sexual function and disasters. Few studies have investigated the COVID-19 pandemic effect on sexual behavior. However, none of them included all FSFI, Beck anxiety, and Beck depression questionnaires that evaluate the female sexual behavior comprehensively. The aim of this study is the determination of the COVID-19 pandemic's effect on female sexual function.

\section{MATERIAL AND METHODS Study design}

From January to February 2020, a cross-sectional and questionnaire-based study was conducted to determine the human papillomavirus (HPV) infection effect on female sexual behavior at the Department of Obstetrics and Gynecology, Dokuz Eylul University Hospital, Izmır, Turkey. The study is under consideration; however, it has not been published yet. Healthy controls of the previous study men-

\section{Corresponding author:}

Orkun llgen

Dokuz Eylul University Hospital, Department of Obstetrics and Gynecology, Izmir, Turkey

phone: (90) 50628844 61; e-mail: mdorkunilgen@gmail.com 
tioned above were selected for the present study. Also, data from the previous study was used. These people were asked if they want to take part in this observational study and those who accept this proposal were welcomed. Local ethics committee approval was obtained for the study (Ethical approval number: 2020/18-27). Written informed consent was obtained from all patients. The patient's and partner's age, parity, BMI, obstetric history and educational level were recorded. Each participant filled the female sexual function index (FSFI), Beck anxiety inventory (BAI), and Beck depression inventory (BDI) questionnaires.

Female participants aged between 18 and 50 were enrolled in the study. Women with the psychiatric disorder or taking psychiatric medication, systemic-chronic disease, obesity (BMI > 30), pregnancy, pelvic organ prolapse, pelvic surgery that causes FSD, premature menopause, dermatologic disorders that affect the genital area, using a medication that impaired sexual function such as anti-hypertensive, anti-arrhythmic, sedative drugs were excluded from the study. COVID-19 positivity or living with COVID-19 positive or suspected individuals were also accepted as an exclusion criterion.

\section{Questionnaire form}

FSFI questionnaire was applied to the patients. Rosen et al. [6], developed this self-report questionnaire to detect FSD by evaluating the female sexual functions. There are six domains and 19 questions that evaluate arousal, desire, orgasm, lubrication, pain, and satisfaction during the last four weeks.

Better sexual functions are associated with higher scores and scores of each domain are in a range between 0 to 5 . The first two questions evaluate sexual desire, then arousal by the following four questions. The next four questions evaluate lubrication followed by three questions evaluating orgasms. There are another three questions to evaluate satisfaction, and lastly, the pain is evaluated by the final three questions. The minimum total score is 1.2 and the maximum total score is 36 points. FSD was associated with lower scores that imply impaired sexual function. The Cronbach alfa coefficient was determined 0.98 in the reliability study for the Turkish version of this test. The meaning of this is that FSFI is a valid and reliable measure of sexual function among Turkish women. FSD was considered with the total scores less than 26 .

$\mathrm{BDI}$ includes 21 questions, each of them rating from 0 to 3 . Scores from 0 to 9 indicate no depression, 10 to 18 mean mild to moderate depression, 19 to 29 show moderate to severe depression, and scores between 30-63 are related to severe depression [7].

BAl consists of 21 questions rating from $0-3$. Scores from 0 to 7 indicate minimal anxiety, 8 to 15 mean mild anxiety,
16 to 25 show moderate anxiety, and scores between 26 and 63 correspond to severe anxiety [8].

\section{Statistical analysis}

The Kolmogorov-Smirnov test was performed as the normality test. Differences between variables were determined by using the paired t-test. Statistic results for continuous variables were presented as means $\pm S D$. $P<0.05$ was considered statistically significant. IBM SPSS Statistics Version 25 was used to analyze the data.

\section{RESULTS}

Ninety-nine sexually active females were enrolled in this study. The mean age of the participants and their partners were 35.1 and 36.7, respectively. The mean BMI was 26.8 and the mean parity rate was 1.8 . Socio-demographic data is summarized in Table 1.

FSFI scores of the participants were higher before the pandemic, however, this finding was not statistically significant (21.8 vs 21.0, $p=0.27$ ). All of the domains of the FSFI (desire, arousal, lubrication, orgasm) were determined lower during the pandemic except satisfaction and pain. Satisfaction and pain scores were determined to be the same before and during the pandemic. However, there was no statistically significant difference ( 3.5 vs $3.3, p=0.20 ; 3.5$ vs $3.3, p=0.08 ; 3.7$ vs $3.5, p=0.22 ; 3.5$ vs $3.4, p=0.50 ; 4.0$ vs 4.0, $\mathrm{p}=0.67 ; 3.3$ vs $3.3, \mathrm{p}=0.93$ ) (Tab. 2).

Comparison of BAl scores to detect whether there is a relationship between anxiety and pandemic showed that the anxiety levels seem significantly increased during the pandemic (11.2 vs $13.3, p<0.01$ ). Additionally, during the pandemic, the BDI score of which higher scores indicate de-

Table 1. Socio-demographic characteristics of the patients

\begin{tabular}{|l|l|}
\hline & $\begin{array}{l}\text { Study group } \\
\text { n: } \mathbf{5 2}\end{array}$ \\
\hline Age $[\mathrm{y}]$ & $35.1 \pm 5.8$ \\
\hline BMI $\left[\mathrm{kg} / \mathrm{m}^{2}\right]$ & $26.8 \pm 3.8$ \\
\hline Number of children & $1.8 \pm 0.6$ \\
\hline Type of delivery, $\mathrm{n}(\%)$ & \\
\hline Vaginal birth & $43(43.4)$ \\
\hline Cesarean section & $56(56.6)$ \\
\hline Educational level, N (\%) & \\
\hline Not-educated & $4(4)$ \\
\hline Primary-Middle school & $15(15.2)$ \\
\hline High school & $63(63.6)$ \\
\hline University & $17(17.2)$ \\
\hline Partner's age [y] & $36.7 \pm 6$ \\
\hline
\end{tabular}

Results are presented as mean \pm SD and number (percentage); BMI — body mass index; $\mathrm{SD}$ - standard deviation 
Table 2. Female Sexual Function Index scores comparison of the participants before and after the COVID-19 pandemic

\begin{tabular}{|l|l|l|l|}
\hline & $\begin{array}{l}\text { Before the } \\
\text { pandemic }\end{array}$ & $\begin{array}{l}\text { During the } \\
\text { pandemic }\end{array}$ & p value \\
\hline Total FSFI score & 21.8 & 21.0 & 0.27 \\
\hline Desire & 3.5 & 3.3 & 0.20 \\
\hline Arousal & 3.5 & 3.3 & 0.08 \\
\hline Lubrication & 3.7 & 3.5 & 0.22 \\
\hline Orgasm & 3.5 & 3.4 & 0.50 \\
\hline Satisfaction & 4.0 & 4.0 & 0.67 \\
\hline Pain & 3.3 & 3.3 & 0.93 \\
\hline
\end{tabular}

Results are presented as mean and number (percentage); FSFI — Female Sexual Function Index

Table 3. Beck Anxiety Inventory and Beck Depression Inventory scores of the participants before and during the COVID-19 pandemic

\begin{tabular}{|l|l|l|l|} 
& $\begin{array}{l}\text { Before the } \\
\text { pandemic }\end{array}$ & $\begin{array}{l}\text { During the } \\
\text { pandemic }\end{array}$ & p value \\
\hline BAI score & 11.2 & 13.3 & $<0.01^{*}$ \\
\hline BDI score & 10.0 & 13.7 & $<0.01^{*}$ \\
\hline
\end{tabular}

Results are presented as mean and number (percentage); BAI — Beck Anxiety Inventory; BDI - Beck Depression Inventory, ${ }^{*}$ - statistically significant

pression were determined increased statistically significant (10.0 vs $13.7, \mathrm{p}<0.01)$ (Tab. 3). Although both increased anxiety and depression, FSFI scores did not decrease significantly during the pandemic.

When the evaluation of whether there is a relation between BAI and FSFI scores, a statistically significant negative correlation was found between BAI and FSFI scores $(p<0.01$; correlation coefficient $=-0.302)$. FSFI scores had a decremental pattern while the BAI scores were increasing. However, statistically significant correlation was not found between BDI and FSFI scores ( $p=0.07$; correlation coefficient $=-0.183$ )

\section{DISCUSSION}

The COVID-19 pandemic has caused a deterioration in social life via elongated quarantine time, disrupted relations between people, increased anxiety, and depression. Evaluation of female sexual function and the possible factors that affect female sexual behavior during the pandemic were the of this study. Despite the increased anxiety and depression, female sexual function was not found significantly different during the pandemic in comparison to before the pandemic.

Stress is one of the main factors that affect sexual desire. However, literature has studies with different results on this issue. Chronic stress or natural disasters such as earthquakes were found to harm female sexual behavior $[5,9]$ menstruation disorders, satisfaction with sexual life, and desire for fertility. RESULTS: The rates of symptoms of lower genital tract infection were higher after than before the earthquake $(50.0 \%$ vs $26.5 \%$. By contrast, another study conducted by Hall et al. [10], has a result of that women has better sexual activity during stressful times. This may be the result of spending more time with their partners at home.

It was shown in previous studies that natural disasters and war impacts female sexual function negatively . In a study that investigated the sexual behavior after a tsunami has a result that $30 \%$ of 1093 participants were suffering from sexual dysfunction [11]. However, in this study a validated FSFI questionnaire was not used. Reduced desire, decreased lubrication, and difficulties to achieve orgasm were the main results of a study that was conducted on female soldiers [12]. The present study is the first study that investigated the female sexual behavior and COVID-19 pandemic relation by using $\mathrm{BAI}$ and $\mathrm{BDI}$, in addition to FSFI to our knowledge. Although FSFI scores were found to have decreased in the present study, this was not statistically significant. Also, alteration of all domains of FSFI including desire, arousal, lubrication, orgasm, satisfaction, and pain before and after the pandemic were not found statistically significant.

Studies show that anxiety and depression has increased during the Covid-19 pandemic [13-15]. In a study conducted by Yeen Huang et al. [16], showed that the prevalence of generalized anxiety disorder and depressive symptoms were $35.1 \%$ and $20.1 \%$, respectively, in the pandemic period. The relationship between depression and female sexual disorder is a well-known fact. Sreelakshmy et al. [17], showed that FSD rates were higher in people with depression regardless of severity and type. BDI was a widely used questionnaire in studies to evaluate whether there was a relationship between sexual function and depression $[18,19]$ sexual function and sexual quality of life in Iranian women with infertility. METHODS: Two hundred and sixty four individuals participated in the study ( 115 healthy controls, 78 with primary and 71 with secondary infertility. On the other hand, women with anxiety have inhibited sexuality [20]. 'Pain, a subunit of sexual dysfunction, was found ten times more frequently in anxiety patients. [21]. BAI was also a commonly used, validated questionnaire in the studies that investigated the link between anxiety and sexual disorder $[22,23]$. In our study, anxiety and depression symptoms seemed significantly increased during the pandemic. Also, a negative correlation was found between FSFI and BAI, as expected. However, a statistically significant correlation was not found between BDI and FSFI scores.

The first limitation of the study is that male partners, who can affect sexual behavior, were not included in this study. Additionally, the present study investigated the short term results of the pandemic's effect on female emotions and 
sexual behavior, different results may be produced with the increased restrictions and elongated pandemic process. On the other hand, the strength of the present study is the investigation of the anxiety and depression status of the participants that can affect sexual behavior in addition to sexual functions.

\section{CONCLUSIONS}

In conclusion, this study demonstrated that women's sexual behavior was not significantly different during the pandemic. However, depressive symptoms and anxiety have increased during the pandemic and the anxiety was determined had a negative correlation with female sexual functions. Further studies are needed to support these results.

\section{Acknowledgments}

None.

\section{Conflict of interests}

The authors declare that they have no conflicts of interest.

\section{Statement of ethics}

The experimental procedures were approved by the Ethics Committee of Dokuz Eylul University, Izmir, Turkey. This study was carried out in consensus with our university's ethics guidelines. The ethics committee approval was obtained for this study (Ethical approval number: 2020/18-27).

\section{Funding}

None.

\section{IRB approval}

This study was carried out in consensus with our university's ethics guidelines.

\section{Informed consent}

Written informed consent for enrollment was obtained from participants.

\section{REFERENCES}

1. Liao X, Wang Bo, Kang Y. Novel coronavirus infection during the 2019-2020 epidemic: preparing intensive care units-the experience in Sichuan Province, China. Intensive Care Med. 2020; 46(2): 357-360, doi: 10.1007/s00134-020-05954-2, indexed in Pubmed: 32025779.

2. Cheng VCC, Wong SC, To KKW, et al. Preparedness and proactive infection control measures against the emerging novel coronavirus in China. J Hosp Infect. 2020; 104(3): 254-255, doi: 10.1016/j.jhin.2020.01.010, indexed in Pubmed: 31962139.

3. Shifren لاL Monz BU, Russo PA et al. Sexual problems and distress in United States women: prevalence and correlates. Obstet Gynecol. 2008; 112(5): 970-978, doi: 10.1097/AOG.0b013e3181898cdb, indexed in Pubmed: 18978095.
4. Kissinger P, Schmidt N, Sanders $C$, et al. The effect of the hurricane Katrina disaster on sexual behavior and access to reproductive care for young women in New Orleans. Sex Transm Dis. 2007; 34(11): 883-886, doi: 10.1097/OLQ.0b013e318074c5f8, indexed in Pubmed: 17579338.

5. Liu S, Han J, Xiao D, et al. A report on the reproductive health of women after the massive 2008 Wenchuan earthquake. Int J Gynaecol Obstet. 2010; 108(2): 161-164, doi: 10.1016/j.ijgo.2009.08.030, indexed in Pubmed: 19892335.

6. Rosen R, Brown C, Heiman J, et al. The Female Sexual Function Index (FSFI): a multidimensional self-report instrument for the assessment of female sexual function. J Sex Marital Ther. 2000; 26(2): 191-208, doi: 10.1080/009262300278597, indexed in Pubmed: 10782451.

7. Ghassemzadeh $\mathrm{H}$, Mojtabai R, Karamghadiri N, et al. Psychometric properties of a Persian-language version of the Beck Depression Inventory-Second edition: BDI-II-PERSIAN. Depress Anxiety. 2005; 21(4): 185-192, doi: 10.1002/da.20070, indexed in Pubmed: 16075452

8. Kaviani H, Mousavi AS. Psychometric properties of the Persian version of Beck Anxiety Inventory (BAI). T Uni Med. 2008; 65(2): 136-140.

9. Hamilton LD, Meston CM. Chronic stress and sexual function in women. J Sex Med. 2013; 10(10): 2443-2454, doi: 10.1111/jsm.12249, indexed in Pubmed: 23841462.

10. Hall KS, Kusunoki $Y$, Gatny $H$, et al. Stress symptoms and frequency of sexual intercourse among young women. J Sex Med. 2014; 11(8): 1982-1990, doi: 10.1111/jsm.12607, indexed in Pubmed: 24894425.

11. Ranawaka DS, Dewaraja R. Tsunami counselling project of the Sri Lanka National Institute of professional counsellors. International Congress Series. 2006; 1287: 79-81, doi: 10.1016/J.ICS.2005.12.037.

12. Gilhooly PE, Ottenweller JE, Lange $\mathrm{G}$, et al. Chronic fatigue and sexual dysfunction in female Gulf War veterans. J Sex Marital Ther. 2001; 27(5): 483-487, doi: 10.1080/713846825, indexed in Pubmed: 11554210.

13. Stein MB. EDITORIAL: COVID-19 and anxiety and depression in 2020 Depress Anxiety. 2020; 37(4): 302, doi: 10.1002/da.23014, indexed in Pubmed: 32266767.

14. Shader RI. COVID-19 and depression. Clin Ther. 2020; 42(6): 962-963, doi: 10.1016/j.clinthera.2020.04.010, indexed in Pubmed: 32362345.

15. Choi EP, Hui BP, Wan EY. Depression and anxiety in Hong Kong during COVID-19. Int J Environ Res Public Health. 2020; 17(10): 3740, doi: 10.3390/ijerph17103740, indexed in Pubmed: 32466251.

16. Huang Y, Zhao N. Generalized anxiety disorder, depressive symptoms and sleep quality during COVID-19 epidemic in China: a web-based cross-sectional survey. Psychiatry Res. 2020; 288: 112954, doi: 10.1101/2020.02.19.20025395.

17. Sreelakshmy K, Velayudhan R, Kuriakose D, et al. Sexual dysfunction in females with depression: a cross-sectional study. Trends Psychiatry Psychother. 2017; 39(2): 106-109, doi: 10.1590/2237-6089-2016-0072, indexed in Pubmed: 28700039.

18. Shahraki Z, Tanha FD, Ghajarzadeh M. Depression, sexual dysfunction and sexual quality of life in women with infertility. BMC Womens Health. 2018; 18(1): 92, doi: 10.1186/s12905-018-0584-2, indexed in Pubmed: 29898709.

19. Barut MU, Coksüer H, Sak S, et al. Evaluation of sexual function in women with hypogonadotropic hypogonadism using the Female Sexual Function Index (FSFI) and the Beck Depression Inventory (BDI). Med Sci Monit. 2018; 24: 5610-5618, doi: 10.12659/MSM.910304, indexed in Pubmed: 30099473.

20. Dèttore $D$, Pucciarelli $M$, Santarnecchi $E$. Anxiety and female sexual functioning: an empirical study. J Sex Marital Ther. 2013; 39(3): 216-240, doi: 10.1080/0092623X.2011.606879, indexed in Pubmed: 23356511.

21. Basson R, Gilks T. Women's sexual dysfunction associated with psychiatric disorders and their treatment. Womens Health (Lond). 2018; 14: 1745506518762664 , doi: $10.1177 / 1745506518762664$, indexed in Pubmed: 29649948

22. Alay I, Kaya C, Karaca I, et al. The effect of being diagnosed with human papillomavirus infection on women's sexual lives. J Med Virol. 2020; 92(8): 1290-1297, doi: 10.1002/jmv.25623, indexed in Pubmed: 31696950.

23. Shahraki Z, Ghajarzadeh M, Ganjali M. Depression, anxiety, quality of life and sexual dysfunction in Zabol women with infertility. Maedica (Bucur). 2019; 14(2): 131-134, doi: 10.26574/maedica.2019.14.2.131, indexed in Pubmed: 31523293. 